\title{
COMPARATIVE STUDY OF FOETAL AND MATERNAL OUTCOME IN CONTROL OF GESTATIONAL HYPERTENSION BY ASSESSING THE MEAN ARTERIAL PRESSURE ( $>105-<125)$ AND CONVENTIONALLY TREATING BLOOD PRESSURE
}

\author{
Ramlath T. P1, Sudhamani $C^{2}$
}

${ }^{1}$ Senior Resident, Department of Obstetrics and Gynaecology, IMCH Government Medical College, Kozhikode, Kerala, India.

${ }^{2}$ Associate Professor, Department of Obstetrics and Gynaecology, IMCH Government Medical College, Kozhikode, Kerala, India.

\begin{abstract}
BACKGROUND
Hypertensive disorders complicate 5\% - 10\% of all pregnancies and contribute greatly to maternal and foetal morbidity and mortality. There is a lack of consensus on the classification/ definition of hypertensive disorders of pregnancy, the Blood Pressure (BP) level at which anti-hypertensive therapy needs to be initiated, the appropriate anti-hypertensive agent and maternal and foetal risk-benefit ratio of treatment. It is generally agreed that severe hypertension (diastolic BP >= $110 \mathrm{mmHg}$ ) requires treatment due to risk of cardiovascular and/or target organ damage. However, in mild-to-moderate hypertension, there is no consensus regarding the blood pressure at which treatment needs to be initiated.

Aim- To compare maternal and foetal outcome of patients in whom anti-hypertensive treatment was started at Mean Arterial Pressure (MAP) of $106-109 \mathrm{mmHg}$ and in whom anti-hypertensive treatment was started at MAP >=110 $\mathrm{mmHg}$.
\end{abstract}

ABSTRACT

\section{MATERIALS AND METHODS}

This is a randomised controlled trial study of patients from Department of Obstetrics and Gynaecology, Government Medical College, Kozhikode, from April 2014 to March 2015. Hundred patients were selected in each group on diagnosing hypertension with the above-mentioned mean arterial pressure and were initiated on anti-hypertensive treatment and managed as per protocol. Statistical analysis was done by SPSS 16. Data was analysed with Chi-square test and Fisher's exact test.

\section{RESULTS}

In our study, 70\% of women in either group were in the age group of 21 - 30 years. Gestational hypertension was found more commonly in primigravidae. There was no significant difference between various drug usages in controlling blood pressure. At initial presentation, the incidence of pre-eclampsia was 37\% in patients with MAP $106-109 \mathrm{mmHg}$ and there was a lesser incidence of proteinuria when anti-hypertensives were initiated in mild hypertension. An improved renal function and an overall reduction in maternal complications were found on early initiation of anti-hypertensive therapy.

\section{CONCLUSION}

Gestational hypertension is more common in primigravidae during $3^{\text {rd }}$ decade of life. Maternal and foetal complications were significantly reduced, and perinatal outcome was better when anti-hypertensives were started with the MAP of $106-109$ mmHg at initial diagnosis. There was no difference between drugs used with regard to control of blood pressure and the need for an additional drug.

\section{KEY WORDS}

MAP, HELLP, IUGR, NICU, IUD, NND, BP.

HOW TO CITE THIS ARTICLE: Ramlath TP, Sudhamani C. Comparative study of foetal and maternal outcome in control of gestational hypertension by assessing the mean arterial pressure (>105 $<125)$ and conventionally treating blood pressure. J. Evolution Med. Dent. Sci. 2018;7(32):3590-3594, DOI: 10.14260/jemds/2018/806

\section{BACKGROUND}

Hypertensive disorders complicate $5 \%-10 \%$ of all pregnancies and contribute greatly to maternal and neonatal morbidity and mortality. It is a multisystem disease of unknown aetiology and there is a constant search for better prognostic factors to predict the progression and severity of the disease. By $19^{\text {th }}$ century, it was recognised that eclampsia is preceded by a collection of circulatory disturbances now known as pre-eclampsia. Pre-eclampsia is best described as a pregnancy-specific syndrome that can affect virtually every

'Financial or Other Competing Interest': None.

Submission 13-06-2018, Peer Review 20-07-2018,

Acceptance 27-07-2018, Published 06-08-2018.

Corresponding Author:

Dr. Sudhamani $C$,

Gulmohar, Karanthur,

Kunnamangalam, Kozhikode-673571, Kerala, India.

E-mail: sudhamen@gmail.com

DOI: $10.14260 /$ jemds $/ 2018 / 806$

\section{(c) (i) $(-$}

organ system ${ }^{1}$ and there is no cure for the disorder when it progresses, other than delivery of the foetus. ${ }^{2}$ Things kept on changing regarding the understanding of this disorder and even the name has changed from toxaemia of pregnancy to pre-eclampsia. ${ }^{3}$ Young and nulliparous women are particularly vulnerable, though race, ethnicity and genetic predisposition have roles. Obesity, multifoetal gestation and age older than 35 years are risk factors. 4 The aim of antihypertensive therapy is to prevent complications associated with hypertension while prolonging the course of pregnancy. It is generally agreed that severe hypertension (Diastolic BP $>=110 \mathrm{mmHg}$ ) requires treatment due to risks of cardiovascular and/or end-organ damage. However, in mildto-moderate hypertension, there is no consensus regarding the blood pressure at which treatment needs to be initiated.

\section{Aim of the Study}

To compare maternal and foetal outcome of patients in whom anti-hypertensive treatment is started at mean arterial pressure (MAP) 106 - $109 \mathrm{mmHg}$ and in whom anti- 
hypertensive treatment is started at mean arterial pressure $>=110 \mathrm{mmHg}$.

\section{MATERIALS AND METHODS}

This is a randomised controlled trial study of 200 cases of hypertension from the Outpatient and Inpatient Department of Obstetrics and Gynaecology, Government Medical College, Kozhikode from April 2014 to March 2015. The sample size was taken for convenience. Hundred patients were selected in each group with diagnosed hypertension during routine antenatal check-up or on admission. Patients were randomly allocated into two groups with 100 patients in each group by sealed sequential number enveloped before the study. Hypertension is defined as a systolic blood pressure $>140$ $\mathrm{mmHg}$ and diastolic blood pressure $>90 \mathrm{mmHg}$ on at least two occasions, measured at least 6 hours apart and the MAP is found. Diastolic blood pressure is defined by Korotkoff phase $\mathrm{V}$.

\section{Study Group}

Group-1: 100 patients.

Group-2: 100 patients.

We recruited 100 patients in each arm and this sample size was taken for convenience. Permission from Institutional Ethics Committee had been taken prior to initiation of the study.

Inclusion Criteria- Antenatal patients with hypertension who are initiated on anti-hypertensive treatment with abovementioned MAP are included.

Exclusion Criteria- Those patients of severe pre-eclampsia already on treatment were excluded. Patients of chronic hypertension and those with co-existing diseases like gestational diabetes mellitus, heart disease, renal disease, auto-immune disorders, multiple pregnancy etc. too were excluded.

Patients were divided into two groups, each comprising of 100 patients. Group 1 contained 100 patients in whom treatment was started at MAP of $106-109 \mathrm{mmHg}$ and Group 2 patients were started on treatment at a MAP of $>=110$ mmHg. Treatment was started at the time of diagnosis in both the groups either with nifedipine, methyldopa or labetalol and were followed up with blood pressure check-up, clinical and symptomatic assessment with routine tests including complete blood count, urine analysis, renal and liver function tests, random blood sugar, serum electrolytes and 24-hour urine protein. Ultrasound and Doppler studies were performed as and when required and both groups were followed up till delivery.

Maternal morbidity was assessed in terms of development of pre-eclampsia, eclampsia, HELLP syndrome, abruptio placentae, end-organ damage, caesarean section, gestational age at delivery, pre-term labour and postpartum haemorrhage. Foetal outcome was assessed by Apgar score, birth weight, IUGR, intrauterine foetal demise, neonatal death, NICU admission and Respiratory Distress Syndrome (RDS).

\section{Statistical Analysis-}

It was done using SPSS version 16.0 for windows. Qualitative data was presented as frequency and percentage and quantitative data as Mean and Standard Deviation (SD) if normal or as median and Interquartile Range (IQR). Comparison between the groups was done by Chi-square or Fisher's exact test for qualitative data and by student's t-test and Mann-Whitney $U$ test for quantitative data. A two-sided p-value of $<0.05$ was considered as statistically significant.

\section{RESULTS}

In our study, $70 \%$ of women in either group were in the age group of 21 - 30 years. Gestational hypertension is found more commonly in primigravidae. In the present study, at initial presentation, the incidence of pre-eclampsia was $37 \%$ in patients with MAP $>=110 \mathrm{mmHg}$ and $7 \%$ in those with MAP 106 - $109 \mathrm{mmHg}$. There was no significant difference between various drug usages in controlling blood pressure. There was a lesser incidence of proteinuria when antihypertensives were initiated in mild hypertension. An improved renal function and an overall reduction in maternal complications were found on early initiation of antihypertensive therapy. Risk was calculated in terms of relative risk and 95\% confidence interval for the same was estimated. A two-sided p-value $<0.05$ was considered as statistically significant. The two groups were comparable with respect to age and parity.

\begin{tabular}{|c|c|c|c|c|c|}
\hline & \multicolumn{4}{|c|}{ Age (Years) } & \multirow{2}{*}{ Total } \\
\hline & $<=20$ & $21-30$ & $31-35$ & 35 & \\
\hline Group 1 & 10 & 70 & 14 & 6 & 100 \\
\hline Group 2 & 13 & 69 & 17 & 1 & 100 \\
\hline Total & 23 & 139 & 31 & 7 & 200 \\
\hline \multicolumn{6}{|c|}{ Table 1. Age } \\
\hline
\end{tabular}

The two groups were comparable with respect to age, $\mathrm{p}=0.235$.

\begin{tabular}{|c|c|c|c|c|c|}
\hline \multicolumn{7}{|c|}{ Gravida } \\
\hline & $\mathbf{1}$ & $\mathbf{2}$ & $\mathbf{3}$ & $>\mathbf{3}$ & Total \\
\hline Group 1 & 57 & 23 & 9 & 11 & 100 \\
\hline Group 2 & 62 & 16 & 17 & 5 & 100 \\
\hline Total & $\mathbf{1 1 9}$ & $\mathbf{3 9}$ & $\mathbf{2 6}$ & $\mathbf{1 6}$ & $\mathbf{2 0 0}$ \\
\hline \multicolumn{7}{|c|}{ Table 2. Parity } \\
\hline
\end{tabular}

Majority of the patients in Group 1 and 2 were primigravidae and comparable with p-value of 0.184 .

\begin{tabular}{|c|c|c|c|c|c|c|}
\hline \multicolumn{7}{|c|}{ Gestational Age (Weeks) } \\
\hline \multirow{2}{*}{ Group 1 1 - 24 } & $\mathbf{2 9 - 3 2}$ & $\mathbf{3 3 - 3 6}$ & $>\mathbf{3 7}$ & Total \\
\cline { 2 - 7 } & 1 & 0 & 13 & 50 & 36 & 100 \\
\hline Group 2 & 5 & 5 & 18 & 37 & 35 & 100 \\
\hline Total & $\mathbf{6}$ & $\mathbf{5}$ & $\mathbf{3 1}$ & $\mathbf{8 7}$ & $\mathbf{7 1}$ & $\mathbf{2 0 0}$ \\
\hline \multicolumn{7}{|c|}{ Table 3. Gestational Age at Diagnosis } \\
\hline
\end{tabular}

In Group 1 and Group 2, 86\% and 72\% respectively were diagnosed after 32 weeks of gestation.

\begin{tabular}{|c|c|c|c|c|c|c|}
\hline \multicolumn{3}{|c|}{ Drug } & \multicolumn{2}{c|}{ MAP } & Total \\
\hline & $\begin{array}{c}\text { Methyl- } \\
\text { dopa }\end{array}$ & Nifedipine & Labetalol & $>\mathbf{1 0 5}$ & $<\mathbf{1 0 5}$ & \\
\hline $\begin{array}{c}\text { Group } \\
1\end{array}$ & 41 & 55 & 4 & 41 & 59 & 100 \\
\hline $\begin{array}{c}\text { Group } \\
2\end{array}$ & 26 & 65 & 9 & 64 & 36 & 100 \\
\hline Total & $\mathbf{6 7}$ & $\mathbf{1 2 0}$ & $\mathbf{1 3}$ & $\mathbf{1 0 5}$ & $\mathbf{9 5}$ & $\mathbf{2 0 0}$ \\
\hline \multicolumn{6}{|c|}{ Table 4. Drugs used and MAP Maintained } \\
\hline \multicolumn{6}{|c|}{}
\end{tabular}




\begin{tabular}{|c|c|c|c|}
\hline Complications & Group 1 & Group 2 & Total \\
\hline $\mathrm{Nil}$ & 80 & 46 & 126 \\
\hline Severe PET & 7 & 37 & 44 \\
\hline Renal dysfunction & 1 & 1 & 2 \\
\hline Impending eclampsia & 2 & 1 & 3 \\
\hline Preterm labour & 2 & 0 & 2 \\
\hline Mild PET & 3 & 3 & 6 \\
\hline $\begin{array}{l}\text { Uncontrolled } \\
\text { hypertension }\end{array}$ & 4 & 5 & 9 \\
\hline HELLP syndrome & 0 & 5 & 5 \\
\hline Liver dysfunction & 1 & 2 & 3 \\
\hline Total & 100 & 100 & 200 \\
\hline
\end{tabular}

P-value significant $=0.003$, relative risk -2.7 , Confidence interval $1.75-4.16$

\begin{tabular}{|c|c|c|c|c|c|c|c|}
\hline & $\bar{z}$ & 怘 & 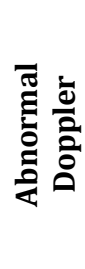 & 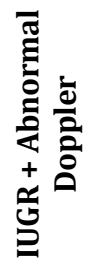 & 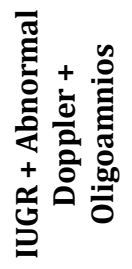 & 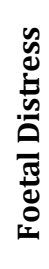 & 胥 \\
\hline Group 1 & 78 & 12 & 5 & 4 & 1 & 0 & 100 \\
\hline Group 2 & 57 & 30 & 8 & 1 & 3 & 1 & 100 \\
\hline Total & 135 & 42 & 13 & 5 & 4 & 1 & 200 \\
\hline
\end{tabular}

Foetal complications were higher in group 2, which was statistically significant; $\mathrm{p}=0.016$.

\begin{tabular}{|c|c|c|c|}
\hline Abnormal Investigations & Group 1 & Group 2 & Total \\
\hline 0 & 86 & 72 & 158 \\
\hline Urine albumin & 7 & 12 & 19 \\
\hline Urine albumin + abnormal LFT & 0 & 1 & 1 \\
\hline Urine albumin + abnormal RFT & 1 & 1 & 2 \\
\hline Urine albumin + low platelet & 1 & 0 & 1 \\
\hline $\begin{array}{c}\text { Urine albumin }+>1 \text { abnormal } \\
\text { result }\end{array}$ & 0 & 1 & 1 \\
\hline Abnormal LFT & 1 & 3 & 4 \\
\hline Abnormal LFT + low platelet & 0 & 2 & 2 \\
\hline Abnormal RFT & 4 & 7 & 11 \\
\hline Low platelet & 0 & 1 & 1 \\
\hline Total & 100 & 100 & 200 \\
\hline \multicolumn{4}{|c|}{ Table 7. Investigations } \\
\hline
\end{tabular}

\begin{tabular}{|c|c|c|c|}
\hline Weeks & Group 1 & Group 2 & Total \\
\hline 0 & 1 & 0 & 1 \\
\hline$<32$ & 4 & 6 & 10 \\
\hline $32-34$ & 1 & 8 & 9 \\
\hline $35-36$ & 17 & 24 & 41 \\
\hline$>=37$ & 75 & 56 & 131 \\
\hline 5 & 2 & 6 & 8 \\
\hline Total & $\mathbf{1 0 0}$ & $\mathbf{1 0 0}$ & $\mathbf{2 0 0}$ \\
\hline \multicolumn{4}{|c|}{ Table 8. Gestational Age at Termination (Weeks) } \\
\hline
\end{tabular}

In group 2, more patients needed termination by 36 weeks of gestation and this is statistically significant. $P$ value $<0.025$.

\begin{tabular}{|c|c|c|c|}
\hline Indication & Group 1 & Group 2 & Total \\
\hline 0 & 12 & 13 & 19 \\
\hline Severe PE & 15 & 35 & 50 \\
\hline Severe PE + foetal cause & 0 & 3 & 3 \\
\hline
\end{tabular}

\begin{tabular}{|c|c|c|c|}
\hline Foetal distress & 1 & 1 & 2 \\
\hline Renal dysfunction & 0 & 2 & 2 \\
\hline HELLP & 0 & 7 & 7 \\
\hline Liver dysfunction & 5 & 0 & 5 \\
\hline Term & 5 & 0 & 5 \\
\hline Foetal cause & 9 & 12 & 21 \\
\hline Gestational HT & 53 & 27 & 80 \\
\hline Total & $\mathbf{1 0 0}$ & $\mathbf{1 0 0}$ & $\mathbf{2 0 0}$ \\
\hline Table 9. Indications for Termination \\
\hline
\end{tabular}

\begin{tabular}{|c|c|c|c|}
\hline Mode & Group 1 & Group 2 & Total \\
\hline Spontaneous & 14 & 11 & 25 \\
\hline Induced & 53 & 55 & 108 \\
\hline LSCS & 33 & 34 & 67 \\
\hline Total & $\mathbf{1 0 0}$ & $\mathbf{1 0 0}$ & $\mathbf{2 0 0}$ \\
\hline \multicolumn{4}{|c|}{ Table 10. Mode of Delivery } \\
\hline
\end{tabular}

Spontaneous labour occurred more commonly in Group 1.

\begin{tabular}{|c|c|c|c|}
\hline Indications & Group 1 & Group 2 & Total \\
\hline 0 & 68 & 65 & 133 \\
\hline Failed induction & 10 & 23 & 33 \\
\hline Uncontrolled BP & 1 & 0 & 1 \\
\hline Eclampsia & 3 & 3 & 6 \\
\hline HELLP & 0 & 1 & 1 \\
\hline Foetal cause & 3 & 2 & 5 \\
\hline Obstetric cause & 13 & 4 & 17 \\
\hline Unfavourable cervix & 0 & 1 & 1 \\
\hline Abruptio placentae & 1 & 0 & 1 \\
\hline MSAF® & 1 & 1 & 2 \\
\hline Total & $\mathbf{1 0 0}$ & $\mathbf{1 0 0}$ & $\mathbf{2 0 0}$ \\
\hline Table 11. Indications for Caesarean Section \\
\hline
\end{tabular}

®Meconium stained amniotic fluid.

\begin{tabular}{|c|c|c|c|}
\hline Outcome & Group 1 & Group 2 & Total \\
\hline Live & 98 & 82 & 180 \\
\hline IUD & 2 & 11 & 13 \\
\hline NND & 0 & 7 & 7 \\
\hline Total & $\mathbf{1 0 0}$ & $\mathbf{1 0 0}$ & $\mathbf{2 0 0}$ \\
\hline \multicolumn{4}{|c|}{ Table 12. Perinatal Outcome } \\
\hline
\end{tabular}

Perinatal outcome was significantly better in Group 1, statistically significant with p-value 0.001 .

\begin{tabular}{|c|c|c|c|}
\hline Weight (Kg) & Group 1 & Group 2 & Total \\
\hline$<1$ & 6 & 11 & 17 \\
\hline $1-1.5$ & 2 & 9 & 11 \\
\hline $1.6-2$ & 9 & 13 & 22 \\
\hline $2.1-2.5$ & 19 & 25 & 44 \\
\hline$>2.5$ & 64 & 42 & 106 \\
\hline Total & 100 & $\mathbf{1 0 0}$ & $\mathbf{2 0 0}$ \\
\hline \multicolumn{4}{|c|}{ Table 13. Birth Weight } \\
\hline
\end{tabular}

\begin{tabular}{|c|c|c|c|}
\hline Apgar & Group 1 & Group 2 & Total \\
\hline Normal & 85 & 82 & 167 \\
\hline Low & 15 & 18 & 33 \\
\hline Total & 100 & 100 & 200 \\
\hline \multicolumn{4}{|c|}{ Table 14. Apgar } \\
\hline RDS & Group 1 & Group 2 & Total \\
\hline Yes & 15 & 17 & 32 \\
\hline No & 85 & 83 & 168 \\
\hline Total & 100 & 100 & 200 \\
\hline \multicolumn{4}{|c|}{ Table 15. RDS } \\
\hline
\end{tabular}




\begin{tabular}{|c|c|c|c|}
\hline NICU & Group 1 & Group 2 & Total \\
\hline Yes & 23 & 35 & 58 \\
\hline No & 77 & 65 & 142 \\
\hline Total & $\mathbf{1 0 0}$ & $\mathbf{1 0 0}$ & $\mathbf{2 0 0}$ \\
\hline \multicolumn{4}{|c|}{ Table 16. NICU Admission } \\
\hline
\end{tabular}

Perinatal outcome was better in Group 1, statistically significant with p-value of 0.001 .

\section{DISCUSSION}

In our study $70 \%$ of women in either group were in the age group of 21 - 30 years, which is similar to the study by Romy Gilliard et al, 5 who also found an increased incidence of gestational hypertension in the third decade of life. The present study showed that gestational hypertension is more common in primigravidae and were $57 \%$ and $62 \%$ in Group 1 and Group 2 respectively, comparable to the results obtained by Caritis S, ${ }^{6}$ Eras JL ${ }^{7}$ and Trupin LS $^{8}$ et al. In all established studies, hypertensive disorders are more common in primigravidae and is dubbed as a disease of primiparity. Majority of the patients with Mean Arterial Pressure (MAP) between $106-109 \mathrm{mmHg}$ at initial presentation were diagnosed near term in both the groups. Saudan $\mathrm{P}$ et $\mathrm{al}^{9}$ in a similar study found that mild gestational hypertension presented at term or near term. Nifedipine was started at diagnosis in 55\% and 65\% of patients in Group 1 and 2. In $41 \%$ and $26 \%$ of patients in Group 1 and 2, methyldopa was used. There was no significant difference between various drug usages in controlling blood pressure. Magee LA et al ${ }^{10}$ in a similar study showed no differences between drugs or drug class in control of gestational hypertension.

In the present study, at initial presentation the incidence of pre-eclampsia was $37 \%$ in patients with MAP $>=110$ $\mathrm{mmHg}$ and $7 \%$ in those with MAP $106-109 \mathrm{mmHg}$. This is statistically significant with $\mathrm{p}$-value $<0.003$. Rubin $\mathrm{P}$ et al ${ }^{11}$ have reported a lesser incidence of proteinuria when antihypertensives were initiated in mild hypertension. In a Cochrane Database review by Abalos $\mathrm{E}$ et al,12 there is no overall difference in the risk of developing pre-eclampsia with early use of anti-hypertensives. There were no cases of HELLP syndrome in patients of Group 1. With MAP >= 110 $\mathrm{mmHg}, 7 \%$ of the patients developed HELLP syndrome which is statistically significant with a p-value of 0.003 , whereas Sibai BM et al13 got $p=0.4$. No statistically significant difference was noted in the incidence of mild pre-eclampsia between the groups, which is similar to the various established studies. Renal dysfunction was slightly higher in patients with MAP >= $110 \mathrm{mmHg}$ at initial diagnosis. Though not statistically significant, this is similar study by Ellenbogen A et $a^{14}{ }^{14}$ where an improvement in renal function was observed in patients with early treatment. Overall maternal complications were reduced in patients in whom antihypertensive therapy was initiated with MAP 106-109 $\mathrm{mmHg}$ at initial presentation. Cochrane database review by Abalos et al $^{12}$ concluded that anti-hypertensive agent halves the risk of developing severe hypertension and there is a lesser need of an additional anti-hypertensive. In Group 2, eight percent of the patients had deranged renal function parameters and $12 \%$ developed proteinuria, which is statistically significant. This correlates with similar studies by
Rubin $\mathrm{P}$ et al, ${ }^{11}$ Ellenbogen et $\mathrm{al}^{14}$ which show improved renal functions with early use of anti-hypertensive therapy.

A statistically significant number of patients (30\%) in Group 2 had Intrauterine Growth Restriction (IUGR), even after excluding those with severe pre-eclampsia at initial presentation. Oligoamnios and abnormal Doppler findings were slightly higher in Group 2. Overall, foetal complications were significantly reduced in the first group. This is in contrast to a similar study by Xiong X et al, ${ }^{15}$ where there was no difference in foetal outcome with early treatment.

In Group 1 and 2, labour was induced in 53\% and 55\% respectively. Majority in Group 1 had gestational hypertension as the main indication, whereas in Group 2 patients had induced labour mainly for the associated complications. This correlates with the study by Gofton EN et al ${ }^{16}$ stating that obstetric intervention rates are much higher in women with hypertensive disorders of pregnancy. In Group 2 patients 34\% had caesarean section, of which $23 \%$ cases were for failed induction, whereas in a majority of cases in Group 1 caesarean section was done for obstetric indications like failed progress of labour and cephalopelvic disproportion. This is similar to a study by Alanis MC et al, ${ }^{17}$ which states that early use of anti-hypertensive drugs may reduce the caesarean section rates for failed induction (17 vs $36 \%$ ). In Group 1 delivery at term was in $75 \%$, whereas with Group 2 it was only $56 \%$. The difference is statistically significant with p-value $<0.001$. This is consistent with the study by Buchbinder A et al 18 that women with severe hypertension had higher rates of preterm delivery.

In Group 2 birth weight above $2.5 \mathrm{~kg}$ was found in $42 \%$, whereas in Group 1 it was $64 \%$ which is statistically significant after excluding preterm babies. According to Hjertberg $\mathrm{R}$ et $\mathrm{al},{ }^{19}$ in a similar study, birth weight were significantly lower when treatment was not started early. In the present study, $11 \%$ of patients in Group 2 and $2 \%$ in Group 1 had Intrauterine Foetal Demise (IUD) and neonatal death of $7 \%$ was observed in Group 2 which is significant. Jabeen $\mathrm{M}$ et $\mathrm{al}^{20}$ observed a difference in neonatal death with early treatment. In Group 2, low Apgar score were noted in $18 \%$ of the babies and $35 \%$ of them needed admission in NICU, which is comparable to the studies by Olusanya BO et $\mathrm{al}^{21}$ and Habli $\mathrm{M}$ et $\mathrm{al}^{22}$ Incidence of Respiratory Distress Syndrome (RDS) was not significantly different in both the groups in contrast to a study by Bowen JR et al, 23 where a reduced incidence was noted with anti-hypertensive treatment. Overall neonatal complications were reduced in Group 1, which is statistically significant. This is in contrast with similar studies in which no significant difference in adverse perinatal outcome is seen between early and late treated groups. Magee LA et $\mathrm{al}^{24}$ in their study "The control of hypertension in pregnancy study pilot trial" could not find a significant difference in perinatal outcome in less tight versus tight control of blood pressure.

\section{CONCLUSION}

In the present study, gestational hypertension is more common in primigravidae during $3^{\text {rd }}$ decade of life. Maternal and foetal complications were significantly reduced, and perinatal outcome was better when anti-hypertensives were started with MAP of $106-109 \mathrm{mmHg}$ at initial diagnosis as compared to initiation of treatment at MAP $>=110 \mathrm{mmHg}$. There was no difference between drugs used with regard to 
control of blood pressure and the need for an additional drug. Though the caesarean section rates were almost comparable between the groups, failed induction as an indication was more in Group 2. The increased rates of complications in Group 2 may be partially due to the inherent probability of developing pre-eclampsia. Limitation of the study was in Group 1 as initiation of anti-hypertensives could have been withheld, but may require intense monitoring which is difficult in our scenario. In a confidential review, it is reported that maternal morbidity in severe pre-eclampsia is mostly due to cerebral haemorrhage. The complications which occurred postpartum were not statistically different between the groups. Close clinical monitoring and more frequent laboratory investigations may go a long way in improving maternal and perinatal outcome in hypertensive disorders of pregnancy.

\section{REFERENCES}

[1] Chesley LC. A short history of eclampsia. Obstetrics \& Gynecology 1974;43(4):599-602.

[2] Cunningham GF, Leveno KJ, Bloom SL, et al. Pregnancy hypertension. Chap - 34. Williams Obstetrics. 24th edn. New York, United States: McGraw-Hill Education/Medical 2014.

[3] Sibai BM, Cunningham FG. Prevention of preeclampsia and eclampsia. In: Lindheimer MD, Roberts JM, Cunningham FG, eds. Chesleys hypertensive disorders of pregnancy. $3^{\text {rd }}$ edn. New York: Elsevier 2009: p. 215.

[4] Eskenazi B, Fenster L, Sidney S. A multivariate analysis of risk factors for preeclampsia. JAMA 1991;266(2):237-41.

[5] Gaillard R, Bakker R, Steegers EA, et al. Maternal age during pregnancy is associated with third trimester blood pressure level: the generation R study. American Journal of Hypertension 2011;24(9):1046-53.

[6] Caritis S, Sibai B, Hauth J, et al. Predictors of preeclampsia in women at high risk. National Institute of Child Health and Human Development Network of Maternal-Fetal Medicine Units. Am J Obstet Gynecol 1998;179(4):946-51.

[7] Eras JL, Saftlas AF, Triche E, et al. Abortion and its effect on risk of preeclampsia and transient hypertension. Epidemiology 2000;11(1):36-43.

[8] Trupin LS, Simon LP, Eskenazi B. Change in paternity: a risk factor for preeclampsia in multiparas. Epidemiology 1996;7(3):240-4.

[9] Saudan P, Brown MA, Buddle ML, et al. Does gestational hypertension become pre-eclampsia? BJOG: An International Journal of Obstetrics \& Gynaecology 1998;105(11):1177-84.

[10] Magee LA, Ornstein MP, Von Dadelszen P. Fortnightly review: management of hypertension in pregnancy. BMJ: British Medical Journal 1999;318(7194):1332-6.

[11] Rubin PC, Butters L, Clark DM, et al. Placebo-controlled trial of atenolol in treatment of pregnancy-associated hypertension. The Lancet 1983;321(8322):431-4.

[12] Abalos E, Duley L, Steyn DW, et al. Antihypertensive drug therapy for mild to moderate hypertension during pregnancy. Cochrane Database Syst Rev 2001;(2):CD002252.
[13] Sibai BM, Barton JR, Sherif A, et al. A randomized prospective comparison of nifedipine and bed rest versus bed rest alone in the management of preeclampsia remote from term. American Journal of Obstetrics and Gynecology 1992;167(4 Pt 1):879-84.

[14] Ellenbogen A, Jaschevatzky O, Davidson A, et al. Management of pregnancy-induced hypertension with pindolol-comparative study with methyldopa. International Journal of Gynecology \& Obstetrics 1986;24(1):3-7.

[15] Xiong X, Mayes D, Demianczuk N, et al. Impact of pregnancy-induced hypertension on fetal growth. American Journal of Obstetrics \& Gynecology 1999;180(1 Pt 1):207-13.

[16] Gofton EN, Capewell V, Natale R, et al. Obstetrical intervention rates and maternal and neonatal outcomes of women with gestational hypertension. American Journal of Obstetrics \& Gynecology 2001;185(4):798-803.

[17] Alanis MC, Robinson CJ, Hulsey TC, et al. Early-onset severe preeclampsia: induction of labor vs elective cesarean delivery and neonatal outcomes. American Journal of Obstetrics \& Gynecology 2008;199(3):262.e1-e6.

[18] Buchbinder A, Sibai BM, Caritis S, et al. Adverse perinatal outcomes are significantly higher in severe gestational hypertension than in mild preeclampsia. American Journal of Obstetrics \& Gynecology 2002;186(1):66-71.

[19] Hjertberg R, Faxelius G, Belfrage P. Comparison of outcome of labetalol or hydralazine therapy during hypertension in pregnancy in very low birth weight infants. Acta Obstetricia Gynecologica Scandinavica 1993;72(8):611-5.

[20] Jabeen M, Yakoob MY, Imdad A, et al. Impact of interventions to prevent and manage preeclampsia and eclampsia on stillbirths. BMC Public Health 2011;11(Suppl 3):S6.

[21] Olusanya BO, Solanke OA. Perinatal outcomes associated with maternal hypertensive disorders of pregnancy in a developing country. Hypertension in Pregnancy 2012;31(1):120-30.

[22] Habli M, Levine RJ, Qian C, et al. Neonatal outcomes in pregnancies with preeclampsia or gestational hypertension and in normotensive pregnancies that delivered at 35,36 , or 37 weeks of gestation. American Journal of Obstetrics \& Gynecology 2007;197(4):406.e1-e7.

[23] Bowen JR, Leslie GI, Arnold JD, et al. Increased incidence of respiratory distress syndrome in infants following pregnancies complicated by hypertension. Australian and New Zealand Journal of Obstetrics and Gynaecology 1988;28(2):109-12.

[24] Magee LA, Von Dadelszen P, Chan S, et al. The control of hypertension in pregnancy study pilot trial. BJOG: An International Journal of Obstetrics \& Gynaecology 2007;114(6):770.e13-e20. 